\title{
Angiotensin Antagonists with Increased Specificity for the Renal Vasculature
}

\author{
Kenneth J. Taub, William J. H. Caldicott, and Norman K. Hollenberg \\ From the Departments of Medicine and Radiology, Peter Bent Brigham Hospital and Harvard \\ Medical School, Boston, Massachusetts 02115
}

A B S T R A C T This study was designed to ascertain whether renal vascular angiotensin receptors differ from other systemic angiotensin receptors and whether, on that basis, antagonists with greater specificity for the renal vasculature can be defined. Femoral and renal blood flow and their responses to angiotensin II (AII) and its heptapeptide analogue, 1-des Asp AII (AIII), were measured with an electromagnetic flowmeter in 26 dogs. For the kidney, the threshold doses of AII and AIII were identical $(2.5 \pm 0.27$ vs. $2.3 \pm 0.35$ $\mathrm{pmol} / 100 \mathrm{ml}$ renal blood flow, with similar doseresponse curves. In contrast, AII had a greater pressor effect $(P<0.001)$ and produced more femoral vasoconstriction $(P<0.001)$ than AIII. All four antagonists studied (1-Sar, 8-Ala AII [P113]; 8-Ala AII; 1-des Asp, 8-Ala AII; 1-des Asp, 8-Ile AII) induced parallel shifts in the renal blood flow response to AII and AIII. P113 induced greater blockade than 8-Ala AII ( $P$ $<0.001)$ which, in turn, was more effective than 1-des Asp, 8-Ala AII $(P<0.001)$. 1-des Asp, 8-Ile AII was as effective as P113. Each analogue induced an identical inhibition of the renal vascular response to AII and AIII. In addition, AII and AIII induced cross-tachyphylaxis. All lines of evidence suggest that AII and AIII act on a single receptor in the kidney, which differs at least functionally from other systemic vascular receptors.

The possibility that heptapeptide analogues represent angiotensin antagonists with greater specificity for the renal vasculature was pursued in a model in which the renin-angiotensin system is activated. Acute, partial thoracic inferior vena caval occlusion was induced in an additional 16 dogs. P113 induced progressive, doserelated hypotension and a limited increase in renal blood flow in this model. The 1-des Asp, 8-Ile AII analogue, conversely, induced a consistent, larger, doserelated renal blood flow increase, with significantly

Received for publication 30 July 1976 and in revised form 22 November 1976. less hypotension over a wide dose range. We conclude that the renal vascular receptor differs sufficiently from systemic angiotensin receptors that heptapeptide analogues of AII will be useful in exploring angiotensin's role in states characterized by disordered renal perfusion and function.

\section{INTRODUCTION}

Several observations have suggested that the renal vascular receptor for angiotensin II (AII) ${ }^{1}$ differs from systemic vascular angiotensin receptors. First, the renal vasculature is especially sensitive to AII (1). Second, the 1-Sar, 8-Ala AII analogue (P113) induces a dose-related reduction in renal blood flow which parallels the response to AII, but exerts only a limited pressor effect $(2,3)$. Third, the observation that 1des Asp AII (AIII) constricts the renal vasculature as effectively as AII (4), despite a limited pressor activity, suggests that this agent does not influence other vascular beds in parallel.

Pharmacologic interruption of the renin-angiotensin system in animals $(5-7)$ and man $(8,9)$ causes significant hypotension in conditions such as cirrhosis, pregnancy, and acute renal failure, which are associated with increased renin levels but a normal blood pressure. The fall in blood pressure induced by the blockers is sufficient to have an important influence on renal blood flow and function, making it impossible to assess the role played by angiotensin in the abnormalities of renal perfusion and function that characterize these conditions. The relatively weak pressor activity of AIII and the similar effects of AII and AIII on the renal vasculature raised the possibility of selective blockade of the renal angiotensin receptor with a structural analogue based on the AIII molecule. This study had two goals: first to characterize the

\footnotetext{
${ }^{1}$ Abbreviations used in this paper: AII, angiotensin II; AIII, 1-des Asp AII; FET, Fisher Exact Test; P113, 1-Sar, 8-Ala AII analogue.
} 
renal vascular angiotensin receptors further; and second, based on the results of the first series of studies, to evaluate the relative effects of octapeptide and heptapeptide analogues of angiotensin on the renal vasculature and blood pressure in a relevant model in which the endogenous renin-angiotensin system had been activated by acute, partial occlusion of the thoracic inferior vena cava.

\section{METHODS}

Studied were performed in 42 dogs, weighing $15-27 \mathrm{~kg}$, studied about $12 \mathrm{~h}$ after withholding fluids. Measurement of blood pressure and blood flow with an electromagnetic flowmeter has been described (10). Anesthesia was induced with $30 \mathrm{mg} / \mathrm{kg}$ i. v. sodium pentobarbital and maintained with additional 5-mg/kg doses as required. Respiration was controlled with a cuffed endotracheal tube and a Harvard respiration pump (Harvard Apparatus Co. Inc., Millis, Mass.) Arterial pressure was measured with a Statham Dc transducer (Statham Instruments Div., Gould Inc., Oxnard, Calif.) from a catheter introduced through a femoral artery. Blood flows in the renal and femoral vascular beds were measured with a Statham electromagnetic flowmeter (M4001 Statham Instruments Div., Gould Inc.) by placing an appropriate-sized flow probe on a segment of the artery. The renal artery was approached through a retroperitoneal incision and the femoral artery through an incision immediately below the inguinal ligament. Zero flow was established by occluding the artery distal to the probe, and probe calibration was performed in vivo. The arteriovenous communications in the paw were excluded with a tourniquet at the ankle when the hind limb was studied.

Characterization of the renal vascular angiotensin receptor. In a series of six dogs, AII (Hypertensin, Ciba Pharmaceutical Company, Summit, N. J.) and AIII (Schwarz Mann Div., Becton, Dickinson \& Co., Orangeburg, N. Y.) were administered intravenously in log-dose increments from 3 to $100 \mathrm{ng} / \mathrm{kg}$ per min to define the relationship between dose and changes in blood pressure, femoral and renal blood flow.

In an additional 20 dogs, the attenuated tip (OD, 1.2 $\mathrm{mm}$; ID, $0.5 \mathrm{~mm}$ ) of a coaxial catheter was introduced into the renal artery to allow intra-arterial administration of the agents. A continuous infusion of $0.9 \%$ saline at $1 \mathrm{ml} / \mathrm{min}$ was maintained in the outer sheath of the coaxial catheter with a motor-driven syringe (Harvard Apparatus Co. Inc.). Dose-response curves were obtained for the renal blood flow reduction induced by intraarterial AII and AIII in a range of $0.01-3,000 \mathrm{ng} / \mathrm{kg}$ in log-dose increments.

The angiotensin antagonists were studied according to two protocols. In one protocol, full AII and AIII doseresponse curves were repeated during the infusion of an angiotensin antagonist into the renal artery via the inner line of the coaxial catheter in 12 dogs. In an additional 14 dogs, the antagonist dose-response curve was defined by using a single, approximately $\mathrm{ED}_{50}$ angiotensin dose (the dose reducing renal blood flow by $50 \%$ ) and defining the antagonist dose as that which induced $50 \%$ inhibition $\left(\mathrm{ID}_{50}\right)$. In this way it was possible to examine the interaction between dose and response over a wide range of both agonist and antagonist concentrations. The antagonists 1-Sar, 8-Ala AII (P113); 8-Ala AII, 1-des Asp, 8-Ala AII; and 1-des Asp 8-Ile AII were diluted in $0.9 \%$ saline and infused at a rate of $0.5 \mathrm{ml} / \mathrm{min}$ in the following dose ranges: P113, 3-300 $\mathrm{ng} / \mathrm{kg}$ per min; 8-Ala AII, 30-300 ng/kg per min; 1-des Asp,
8-Ala AII, 30-3,000 ng/kg per min; 1-des Asp, 8-Ile AII, 3-100 $\mathrm{ng} / \mathrm{kg}$ per min. Recovery of response to angiotensin was assured before proceeding with another antagonist when different antagonists were used in the same dog.

Tachyphylaxis to AII (three studies) or AIII (two studies) was induced with a continuous $5-10-\mu \mathrm{g} / \mathrm{min}$ infusion of either agent into the renal artery. This dose resulted in an acute, approximately $75 \%$, reduction in renal blood flow which gradually returned to within $30 \%$ of control over the next 5-10 min when it stabilized. Responses to bolus doses of both AII and AIII (10 ng/ $/ \mathrm{kg})$ and norepinephrine $(10 \mu \mathrm{g})$ (Levophed, Winthrop Laboratories, New York) were assessed before initiating the continuous angiotensin infusion and repeated after blood flow stabilized during the continued angiotensin infusion.

Responses to angiotensin antagonists in the caval dog. The relative effects on renal blood flow and blood pressure of interrupting the renin-angiotensin system with the octapeptide, P113, and the heptapeptide, 1-des Asp, 8-Ile AII, were evaluated in a model in which the renin-angiotensin system is activated and in which P113 causes hypotension; acute, partial thoracic inferior vena caval occlusion (11). Briefly, in 16 anesthetized dogs, a balloon-tipped catheter was placed in the thoracic vena cava under fluoroscope guidance. After a control period, the balloon was inflated to increase lower abdominal caval pressure by $7.5-10 \mathrm{~mm}$ $\mathrm{Hg}$ and caval pressure was maintained at this level by adjusting a micrometer syringe on the catheter. P113 (10 dogs) or 1-des Asp, 8 Ile AII (6 dogs) was then infused intravenously in log-dose increments over the range of 30-3,000 $\mathrm{ng} / \mathrm{kg}$ per min. Each animal received at least three doses and each dose was maintained for at least $5 \mathrm{~min}$. Arterial and caval pressure and renal blood flow were monitored continuously in each animal.

Means have been presented with the standard error of the mean as the index of dispersion. Tests of statistical significance were carried out with the $t$ test, analysis of variance or for regression, where applicable. In some cases, indicated in the text, the results were assessed with a nonparametric technique, the Fisher Exact Test (FET). The null hypothesis was rejected when a $P$ value of less than 0.05 was obtained (12).

\section{RESULTS}

Characterization of the renal vascular angiotensin receptor. The responses of arterial blood pressure, femoral and renal blood flows to AII and AIII infused intranveously are summarized in Fig. 1. AII was considerably more active as a pressor agent over the entire dose range $(P<0.001 ; \mathrm{FET})$. For example, $100 \mathrm{ng} / \mathrm{kg}$ per min of AIII induced a pressor response of $15.7 \pm 2.1 \mathrm{~mm} \mathrm{Hg}$. The AII dose required to induce this change in blood pressure was approximately 20 $\mathrm{ng} / \mathrm{kg}$ per min. The difference in the response of the femoral vascular bed to AII and AIII was even larger $(P=0.001 ; \mathrm{FET})$. AIII at $100 \mathrm{ng} / \mathrm{kg}$ per min reduced femoral blood flow $18.1 \pm 5.9 \mathrm{ml} / \mathrm{min}$. The AII dose required to induce this response was approximately $10 \mathrm{ng} / \mathrm{kg}$ per min. Conversely, the renal vascular bed responded similarly to the two agents; a statistically significant difference could not be demonstrated $(P$ $>0.2$; FET).

The similarity in the response of the renal vascular 


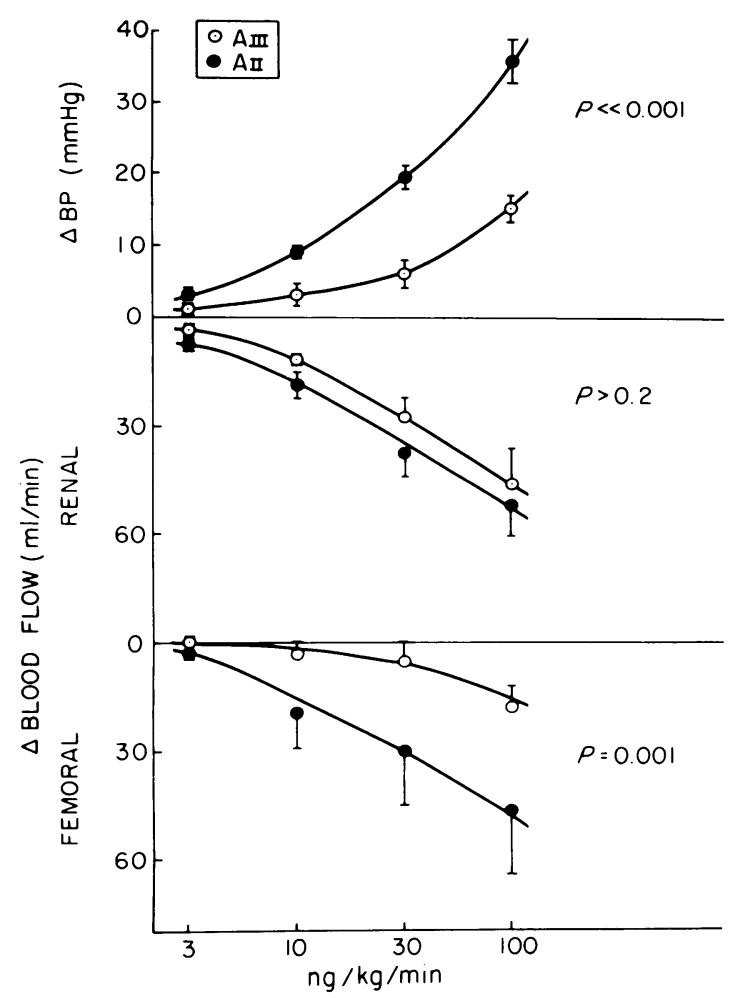

FIgure 1 Dose-response curves to intravenous AII and AIII. Changes in blood pressure, and renal and femoral blood flow produced by graded intravenous infusions of AII and AIII. Each point represents the mean \pm SEM in six dogs.

bed to AII and AIII was explored in greater detail by examining the responses to injections made directly into the renal artery, where complicating systemic effects could be avoided. The threshold AII dose inducing a renal blood flow reduction defined by linear regression was $2.5 \pm 0.27 \mathrm{pmol} / \mathrm{kg}$ per $100 \mathrm{ml}$ renal blood flow, identical to the AIII threshold $(2.3 \pm 0.35$; $t=0.54 ; P>0.6$; Fig. 2). The entire dose-response curves were identical.

As a second approach to comparing the receptors for AII and AIII, tachyphylaxis of the renal vasculature was induced to one agent, and cross-tachyphylaxis to the other was assessed (Fig. 3). After a marked initial reduction in renal blood flow in each case, flow returned progressively towards the control level within minutes, generally stabilizing at a somewhat reduced level within 5-10 min. Responsiveness to norepinephrine was well sustained (Fig. 3). However, bolus injections of AII and AIII, which initially induced a $50 \%$ reduction in renal blood flow, both showed a markedly blunted, barely recognizable response at this time. Thus, cross-tachyphylaxis of the renal vasculature which was specific for the angiotensins was demonstrated.

As a third approach to characterizing the renal receptor, and in search of more specific antagonists, a series of analogues which act as competitive antagonists was used. Each analogue induced parallel shifts in the dose-response curves to both AII and AIII and did not influence the renal vascular responses to norepinephrine, thus satisfying the criteria for competitive antagonists. To facilitate comparison of the antagonists, percent inhibition curves were constructed for the effect of each antagonist on responses to the $E D_{50}$ of both AII and AIII; i.e., that dose which under control conditions induced a $50 \%$ blood flow reduction. Tracings of serial responses to $10 \mathrm{ng} / \mathrm{kg}$ of AII during the infusion of graded doses of one of the antagonists are shown in Fig. 4. The responses to all agents are summarized in Figs. 5 and 6. P113 was the most potent antagonist: the antagonist dose which induced 50\%

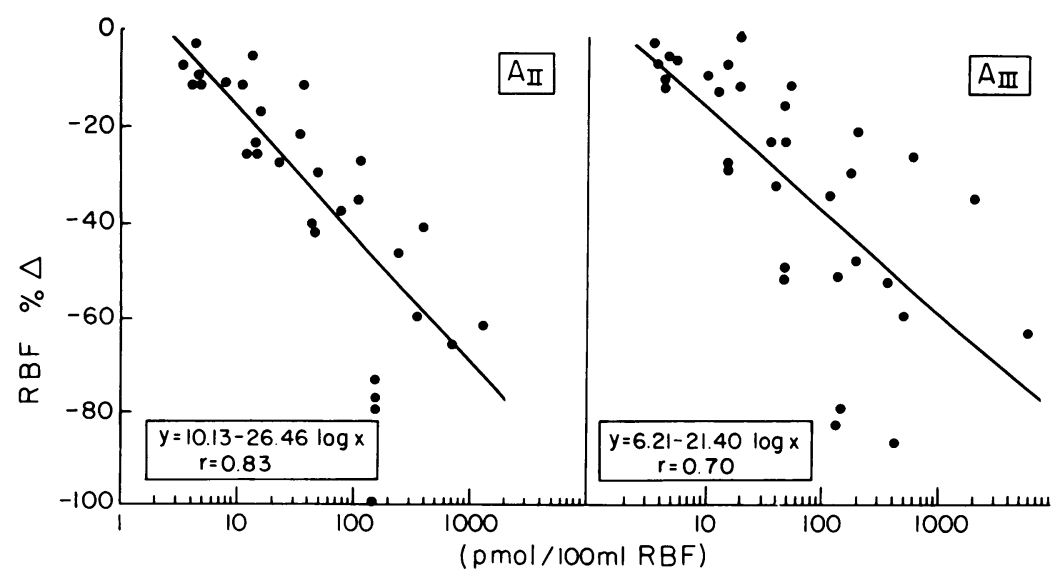

Figure 2 Dose-response curves for renal blood flow (RBF) changes induced by bolus injections of AII and AIII made directly into the renal artery. No significant difference between responses to AII and AIII was demonstrable. 


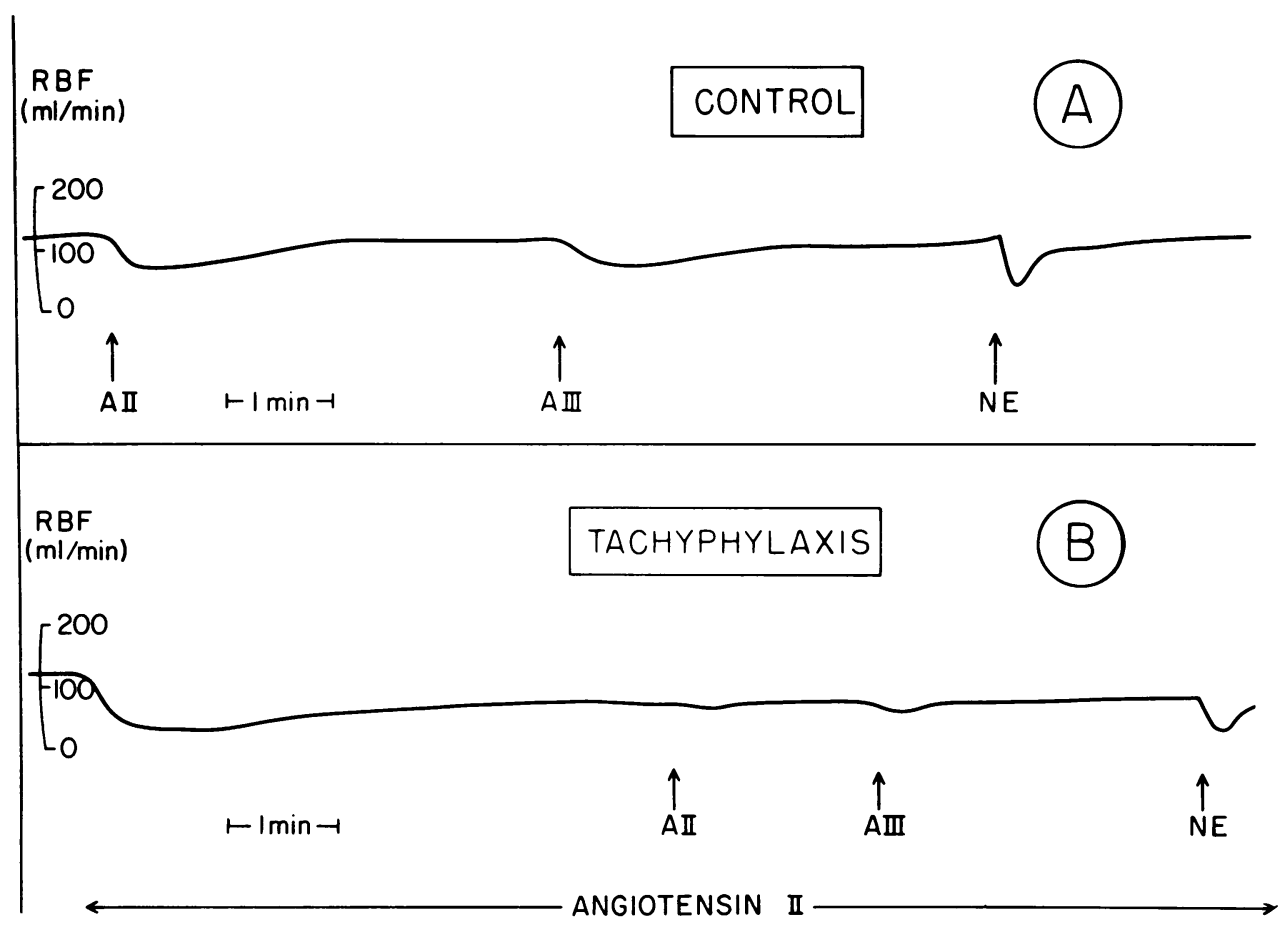

FIgURE 3 Demonstration of renal vascular cross-tachyphylaxis to AII and AIII. (A) Changes in renal blood flow (RBF) induced by $10-\mathrm{ng} / \mathrm{kg}$ bolus injections of AII and AIII and $10 \mu \mathrm{g}$ of norepinephrine (NE), made directly into the renal artery. (B) Continuous infusion of AII (10 $\mu \mathrm{g} / \mathrm{min}$ intraarterial) produced an initial marked fall in RBF followed by spontaneous return towards control; cross-tachyphylaxis was demonstrated by loss of responsiveness to AII and AIII and specificity by sustained response to NE during tachyphylaxis.

inhibition $\left(\mathrm{ID}_{50}\right)$ of responses to AII was about $10 \mathrm{ng} / \mathrm{kg}$ per min. 8-Ala AII was significantly less active than P113 $(P<0.01 ;$ FET $)$ with an ID $_{50}$ of approximately $100 \mathrm{ng} / \mathrm{kg}$ per min. The 1-des Asp, 8-Ala AII analogue was the least effective blocker, being significantly less active than 8-Ala AII $(P<0.001 ;$ FET $)$ with an ID $_{50}$ of about $400 \mathrm{ng} / \mathrm{kg}$ per min. The percent inhibition induced by 1-des Asp, 8-Ile AII was identical to P113 (Fig. 6). Each antagonist induced inhibition of the renal vascular response to AIII which was identical to the inhibition of the response to AII, providing a third line of evidence for identity of the AII and AIII renal vascular angiotensin receptor.

Responses to angiotensin antagonists in the caval dog. Equality of inhibition of renal vascular responses to angiotensin induced by P113 and 1-des Asp, 8-Ile AII facilitated the comparison of the effects of heptapeptide and octapeptide analogue on blood pres-

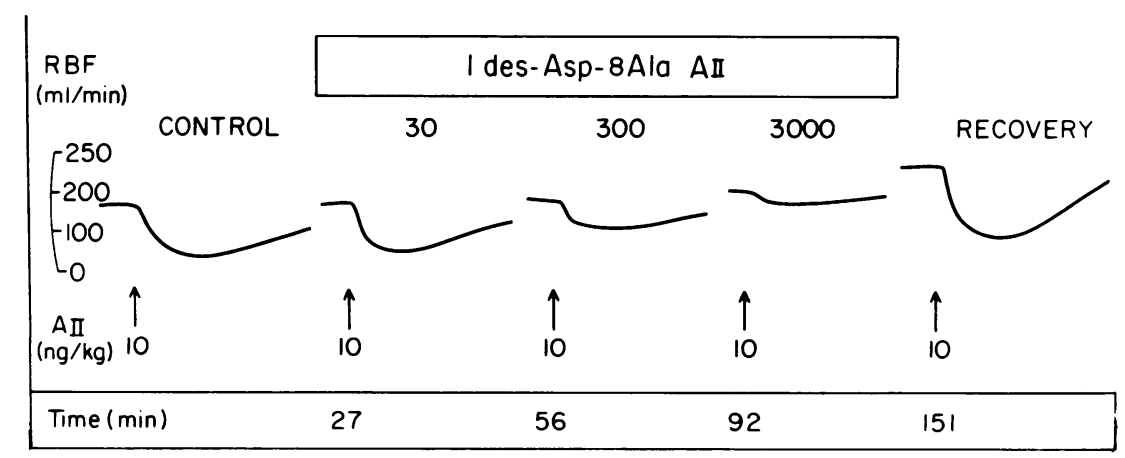

FIGURE 4 Tracings of the renal vascular response to AII during antagonist infusion. Progressive inhibition of renal blood flow (RBF) response to an intraarterial bolus of AII (10 $\mathrm{ng} / \mathrm{kg}$ ) was produced by graded infusions of the AIII analogue (1-des Asp, 8-Ala AII), infused at rate of 30,300 , and $3,000 \mathrm{ng} / \mathrm{kg}$ per $\mathrm{min}$. 


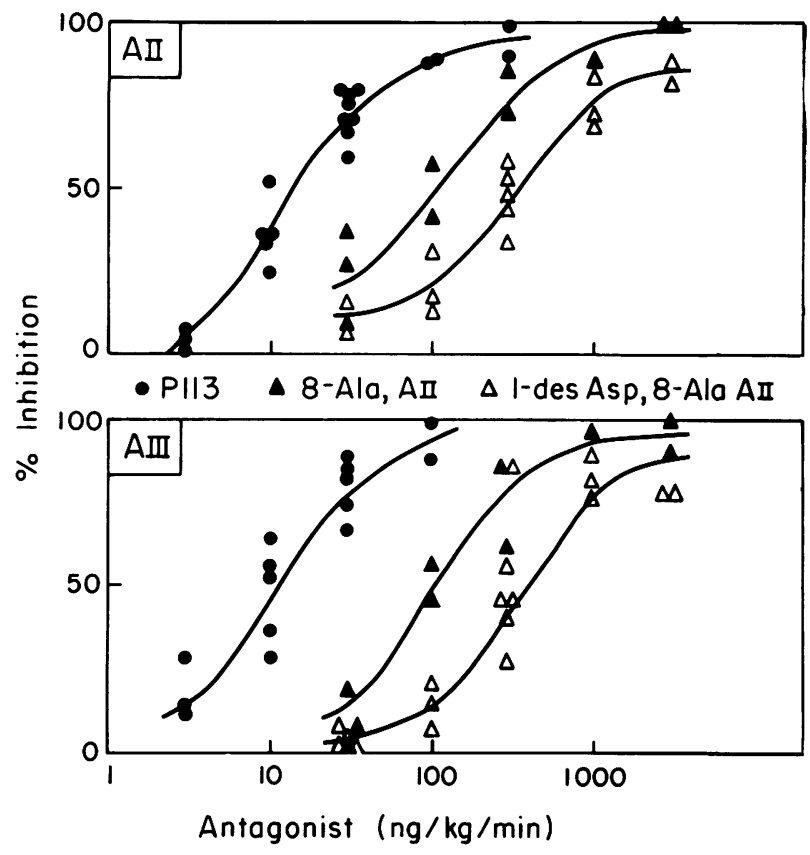

FIGURE 5 Inhibition of renal blood flow change produced by three antagonists with 8-Ala substitution. AII and AIII were injected into the renal artery as a $10-\mathrm{ng} / \mathrm{kg}$ bolus, and the antagonists were infused into the renal artery continuously through a coaxial catheter. Percent inhibition was calculated from the formula $(100)(C-R) / C$. C = control renal blood flow response. $R=$ response during infusion of antagonist. Identical blockade of AII and AIII was induced by the three analogues over a wide range of antagonist potency.

sure and renal blood flow in dogs with acute, partial thoracic inferior vena caval occlusion, a model in which the renin-angiotensin system is activated. Tracings of typical experiments with each agent are shown in Fig. 7 and the dose-response relationships for the two analogues in all dogs are summarized in Fig. 8.

Acute caval occlusion reduced mean arterial pressure from $138 \pm 5.7$ to $108 \pm 8.3 \mathrm{~mm} \mathrm{Hg}$ in the dogs which were to receive $\mathrm{P} 113$ and from $145 \pm 5.3$ to $109 \pm 4.2$ $\mathrm{mm} \mathrm{Hg}$ in the dogs which were to receive the heptapeptide analogue. Renal blood flow fell from $3.93 \pm 0.24$ to $2.65 \pm 0.27 \mathrm{ml} / \mathrm{min}$ per $\mathrm{g}$ in the dogs which were to receive $\mathrm{P} 113$ and from $4.19 \pm 0.58$ to $3.39 \pm 0.63 \mathrm{ml} / \mathrm{min}$ per $g$ in the dogs which were to receive the heptapeptide analogue. The responses in the representative dogs presented in Fig. 7 were typical.

In the dog shown in Fig. 7., a P113 dose of 300 $\mathrm{ng} / \mathrm{kg}$ per min was associated with a small, but unequivocal increase in renal blood flow despite the fall in arterial pressure. Increasing dose was associated with a continuing decrement in arterial pressure and with the largest dose used, 3,000 $\mathrm{ng} / \mathrm{kg}$ per min, a reversal in the direction of the renal blood flow response occurred. A similar pattern was evident in each dog receiving $\mathrm{P} 113$, but the dose which increased renal blood flow differed in each dog. As a result, no P113 dose induced an increase in average renal blood flow for all dogs and flow was reduced significantly $(P$ $<0.05$ ) at a P113 dose of $3 \mu \mathrm{g} / \mathrm{kg}$ per min (Fig. 8). The dose-related hypotension which occurred with P113 was significant at $100 \mathrm{ng} / \mathrm{kg}$ per $\min (P<0.01$; Fig. 8).

In contrast, infusion of the heptapeptide analogue after partial caval occlusion was associated with a better-sustained arterial blood pressure (Figs. 7 and 8) and a dose-related, well-sustained blood flow increase. The blood flow increase (Fig. 8) became significant at a dose of $300 \mathrm{ng} / \mathrm{kg}$ per min $(P<0.01)$ and increased with increasing dose. In individual animals, increasing the heptapeptide dose did result in an arterial blood pressure fall, which limited the blood flow response, as is evident in Fig. 7.

For the group as a whole, a significant increase in renal blood flow was not identified at any P113 dose (Fig. 8), because the optimal dose varied in different dogs. A flow increase which occurred in one dog at a given dose was offset by a greater tendency for blood pressure and flow to fall at that dose in another dog. When the maximum flow increase induced by P113 was assessed, an average increase of 0.25 $\pm 0.19 \mathrm{ml} / \mathrm{min}$ per $\mathrm{g}$ was found. Despite an identical capacity to block renal vascular responses to AII, the heptapeptide analog induced significantly less hypotension. Perhaps as a consequence, the renal

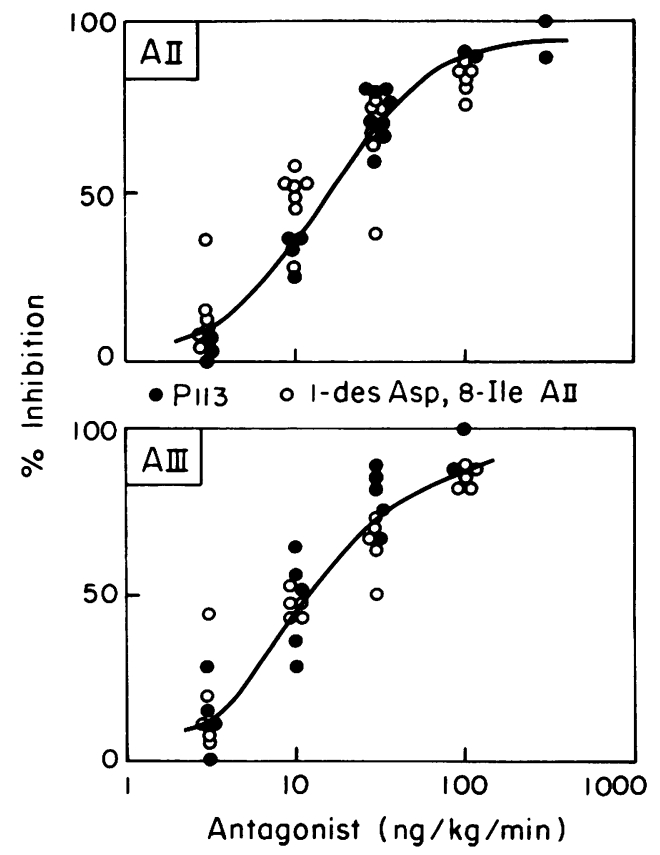

Figure 6 P113 and 1-des Asp, 8-Ile AII induced identical blockade of AII and AIII, and were equipotent. 
vascular response to this analogue was potentiated, with a maximal flow increase of $0.63 \pm 0.23 \mathrm{ml} / \mathrm{g}$ per min which occurred despite a $10-20 \mathrm{~mm} \mathrm{Hg}$ reduction in arterial pressure.

\section{DISCUSSION}

Circumstantial evidence reviewed in the introduction raised the possibility that the renal receptor differs sufficiently from systemic angiotensin receptors such that angiotensin analogues with greater specificity for the kidney could be found. In particular, the observation that AII and AIII had a similar influence on the renal vasculature despite the striking differences in their capacity to raise blood pressure (4), provided a clue to the avenue which might lead to antagonists with greater specificity for the kidney. The primary thrust of this study was to compare the systemic and renal responses to AII and AIII, to characterize the renal vascular receptor to these angiotensins more specifically and, based on new evidence for an identical renal receptor, to establish the principle that heptapeptide analogs would have greater specificity for the renal than the systemic vasculature.

Three unrelated lines of evidence now suggest an identical renal receptor for AII and its 1-des Asp heptapeptide analogue (AIII). First, we confirmed identical responsiveness of the renal vasculature to AII and AIII (4), and extended that observation by demonstrating a difference between the renal and femoral beds. Second, we demonstrated cross-tachyphylaxis between AII and AIII in the renal vascula-
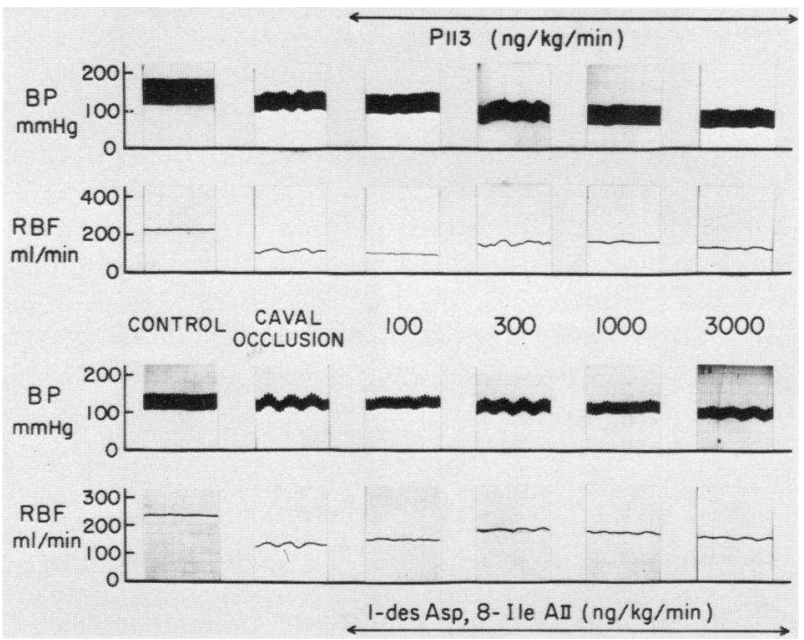

FIGURE 7 Tracings of the effect of partial thoracic caval occlusion and angiotensin analogue on blood pressure and renal blood flow (RBF) in two dogs. (Top) A biphasic blood flow response and progressive, dose-related hypotension occurred with P113. (Bottom) 1-des Asp, 8-Ile AII induced less hypotension and a more striking, better-sustained renal vascular response.
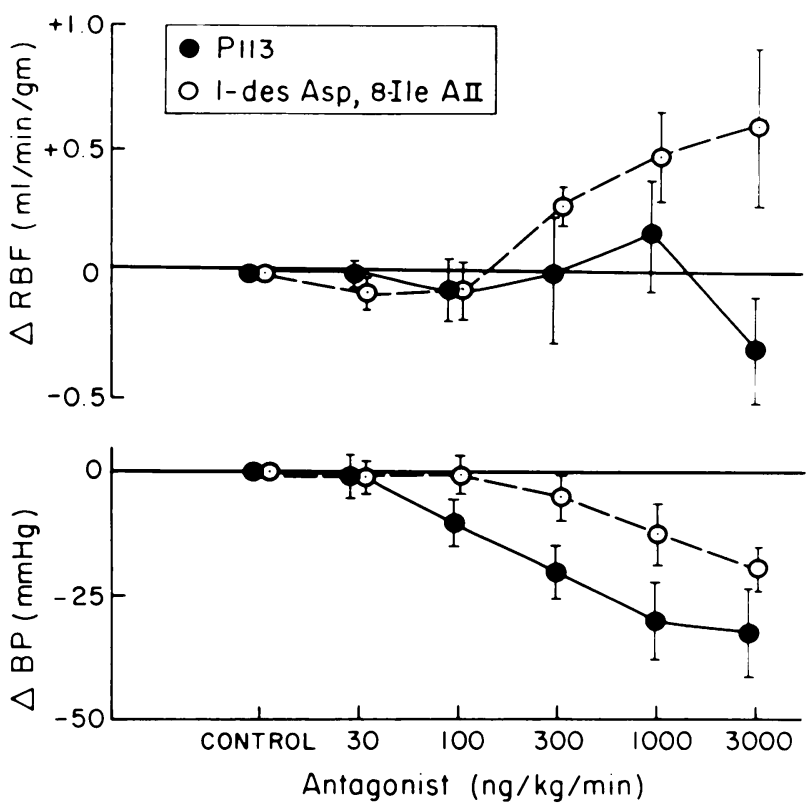

Figure 8 Cumulative dose-response curves to P113 (10 dogs) and 1-des Asp, 8-Ile AII (6 dogs) infused during caval occlusion. The heptapeptide analogue induced significantly less hypotension $(P<0.02)$ and a significantly larger blood flow increase $(P<0.025)$.

ture. Third, the identical inhibition of renal vascular responses to AII and AIII by their respective analogues provided unequivocal evidence. In addition, the analogue study identified a heptapeptide analogue, 1-des Asp, 8-Ile AII, which was as effective as P113 in blocking renal vascular responses to angiotensin. This observation facilitated a comparison of the relative influence of an octapeptide and a heptapeptide analogue on the systemic and renal vasculature in a model of the conditions described below, the caval dog.

Circumstantial evidence has implicated renal vasoconstriction due to angiotensin in the abnormalities of renal perfusion and function which characterize a number of states including acute renal failure (6), thoracic caval occlusion $(7,13)$, hepatic cirrhosis (14, $15)$, and congestive heart failure $(16,17)$. In each state the renin-angiotensin system is activated, the resultant circulating AII concentrations are adequate to induce extreme renal vasoconstriction $(2,18,19)$, renal vasoconstriction is present $(6,7,14,16)$, and where it has been tested, the normal renal response to angiotensin is either blunted or reversed (13-15). The latter observation in particular has been thought to reflect occupation of angiotensin receptors. The development of angiotensin antagonists provided a more direct approach to defining the specific role of angiotensin in the renal abnormality and, if successful, new approaches to therapy in these syndromes. 
Unfortunately, in each of these conditions, administration of the angiotensin antagonist has been associated with hypotension sufficiently consistent and severe as to limit the renal response (6-8).

Partial occlusion of the thoracic inferior vena cava in the dog has been widely employed as a model in which there is disordered volume homeostasis, abnormalities of renal perfusion and function, and activation of the renin-angiotensin system $(7,11)$. As yet, there is no broad agreement as to the mediator of the renal response. Two groups have employed angiotensin antagonists to assess the renal response in this model, with conflicting results $(7,20)$. Freeman et al. (7) reported an increase in renal blood flow with a low dose of Pll3 $(0.2 \mu \mathrm{g} / \mathrm{kg}$ per min) infused into the renal artery. Hypotension and a reduction in renal blood flow occurred with higher doses. Slick et al. (20) reported that the same agent in the same dose did not influence renal perfusion, assessed as $\rho$-aminohippurate clearance. Several observations in this study help to explain the apparent conflict. The use of graded P113 doses demonstrated an increase in renal blood flow in response to P113 infused intravenously. The flow increase generally occurred with small doses and was dissipated with increasing P113 dose, presumably at least in part because of resultant hypotension. In view of our observation that different doses of P113 were optimal in different animals, it is not surprising that a study based on a single dose failed to document the renal response. A contributing factor may also have been the intrinsic activity of $\mathrm{P} 113$, which is a partial agonist in the kidney $(2,3,18)$. In general, partial agonists show the greatest blockade at low doses, and their intrinsic activity tends to dominate the response with increasing doses (21).

The heptapeptide analogue induced an even more striking renal vascular response associated with a better sustained blood pressure level in the caval dog. These results suggest that angiotensin was involved both in sustaining blood pressure and in the renal blood flow reduction in this model. The role played by angiotensin in the abnormalities of renal function in this model, and in others, remains to be defined. An unequivocal demonstration will demand an angiotensin antagonist which induces a maximal renal vascular response in the absence of hypotension, and which is effectively free of intrinsic activity on the kidney at the optimal dose. Certainly heptapeptide analogues defined in this study represent an improvement over P113, but they are by no means ideal. The relative inactivity of the 1-des Asp, 8-Ala analogue precluded its use, since such large doses would be required. Only limited amounts of each analogue were available. The isoleucine heptapeptide analogue, in common with isoleucine octapeptide analogues, was much more effective as an antagonist: unfortunately, as for the isoleucine octapeptide analogues $(22,23)$, the agent had considerable intrinsic activity on the renal vasculature.

Observations made in this study also provide insight into the role played by angiotensin III as a determinant of renal vascular responses to angiotensin. In the case of aldosterone release from the adrenal, it has been suggested that AIII represents the hormone and that AII is a prohormone or precursor (24) The major evidence in that system is the greater efficacy of heptapeptide analogues in blocking the adrenal response to AII. In this study, the heptapeptide analogues were not more efficacious in blocking the renal vascular response to AII. Moreover, the identical blockade of renal vascular responses to AII and AIII induced by P113, an analogue resistant to degradation by aminopeptidase, suggests that conversion of AII to AIII is not required for the action of AII on the renal vasculature.

Antagonists have been extremely useful in characterizing receptors for a wide variety of agonists, including the adrenergic, cholinergic, and histamine systems (25). Earlier investigation has suggested that the angiotensin receptors in myocardium, the central nervous system, the adrenal, and vascular smooth muscle differ rather strikingly $(21,26-29)$. This study has extended those observations to indicate that within the vascular system itself there must be functional heterogeneity among angiotensin receptors. As a result, heptapeptide analogues provide entrée to greater specificity for the renal vasculature. The potential utility of angiotensin antagonists in reversing the renal response in a number of syndromes including acute renal failure (6), hepatic cirrhosis $(7,8)$, and congesitve heart failure (personal observation) has been limited by the attendant hypotension. It appears that activation of the renin-angiotensin system contributes to the maintenance of blood pressure in these syndromes, as well as others $(5,9)$. In view of the accumulating evidence that angiotensin plays a role in the pathogenesis of these processes, this avenue merits further investigation.

\section{ACKNOWLEDGMENTS}

It is a pleasure to acknowledge the assistance of Mss. I. Dowgialo, E. Gonski, K. Hinrichs, B. Mahoney, L. Rodolph, and Mr. R. Johnson, and to express our gratitude to Doctors R. Keenan, A. Castellion, and G. Denning of the Norwich Pharmacal Company for supplying the angiotensin analogues.

This research was supported by grants from the National Institutes of Health (GM 18674, HL 14944, HL 11668, HE 05832) and the U. S. Army Research and Development Command (DAMD 1774 4023). 


\section{REFERENCES}

1. Mandel, M. J., and L. A. Sapirstein. 1962. Effect of angiotensin infusion on regional blood flow and regional vascular resistance in the rat. Circ. Res. 10: 807-816.

2. Hollenberg, N. K., G. H. Williams, B. Burger, I. Ishikawa, and D. F. Adams. 1976. Blockade and stimulation of renal, adrenal, and vascular angiotensin II receptors with 1-Sar-8-Ala angiotensin II in normal man. J. Clin. Invest. 57: 39-46,

3. Mimran, A., K. J. Hinrichs, and N. K. Hollenberg. 1974. Characterization of smooth muscle receptors for angiotensin: Studies with an antagonist. Am. J. Physiol. 226: $185-190$

4. Freeman, R. H., J. O. Davis, and T. E. Lohmeier. 1975. Des-1-Asp-Angiotensin II. Possible intrarenal role in homeostasis in the dog. Circ. Res. 37: 30-34.

5. Bay, W. H., and T. F. Ferris. 1975. Studies of the circulation during pregnancy. Abstract from the American Society of Nephrology. 8: 41. (Abstr.)

6. Ishikawa, I., and N. K. Hollenberg. 1976. Pharmacologic interruption of the renin angiotensin system in myohemoglobinuric acute renal failure. Kidney Int. 5: 183-190.

7. Freeman, R. H., J. O. Davis, S. J. Vitale, and J. A. Johnson. 1973. Intrarenal role of angiotensin II. Homeostatic regulation of renal blood flow in the dog. Circ. Res. 32: 692-698.

8. Schroeder, E. T., G. H. Anderson, S. H. Goldman, and D. H. P. Streeten. 1975. Effects of angiotensin II (AII) blockade with 1-sar-8-ala AII (Saralasin) in patients with cirrhosis and ascites. Abstract from the American Society of Nephrology. 8: 47. (Abstr.)

9. Sasaki, H., H. Okumura, H. Ikeda, T. Kawasaki, and K. Fukiyama. 1976. Hypotensive response to angiotensin II analogue in Bartter's syndrome. N. Engl. J. Med. 294: $611-612$.

10. Caldicott, W. J. H., N. K. Hollenberg, and H. L. Abrams. 1970. Characteristics of response of renal vascular bed to contrast media. Evidence for vasoconstriction induced by renin-angiotensin system. Invest. Radiol. 5: 539-547.

11. Kilcoyne, M. M., and P. J. Cannon. 1971. Influence of thoracic caval occlusion on intrarenal blood flow distribution and sodium excretion. Am. J. Physiol. 220: 12201230.

12. Snedecor, G. W., and W. G. Cochran. 1967. Statistical Methods. Iowa State University Press, Ames, Iowa. 6th edition.

13. Cannon, P. J., R. P. Ames, and J. H. Laragh. 1966. Indirect action of angiotensin infusion to inhibit renal tubular sodium reabsorption in dogs. Am. J. Physiol. 211: $1021-1030$.

14. Gutman, R. A., A. W. Forrey, W. P. Fleet, and R. E. Cutler. 1973. Vasopressor-induced natriuresis and altered intrarenal haemodynamics in cirrhotic man. Clin. Sci. Mol. Med. 45: 19-34.

15. Laragh, J. H., P. J. Cannon, C. J. Bentzel, A. M. Sicinski, and J. I. Meltzer. 1963. Angiotensin II, norepinephrine, and renal transport of electrolytes and water in normal man and in cirrhosis with ascites. J. Clin. Invest. 42: 1179-1192.

16. Freeman, R. H., J. O. Davis, W. S. Spielman, and T. E. Lohmeier. 1975. High-output heart failure in the dog: Systemic and intrarenal role of angiotensin II. Am. J. Physiol. 229: 474-478.

17. Watkins, L., Jr., J. A. Burton, E. Haber, J. R. Cant, F. W. Smith, and A. C. Barger. 1976. The reninangiotensin-aldosterone system in congestive failure in conscious dogs. J. Clin. Invest. 57: 1606-1617.

18. Burger, B. M., T. Hopkins, A. Tulloch, and N. K. Hollenberg. 1976. The role of angiotensin in the canine renal vascular response to barbiturate anesthesia. Circ. Res. 38: 196-202.

19. Hollenberg, N. K., H. S. Solomon, D. F. Adams, H. L. Abrams, and J. P. Merrill. 1972. Renal vascular responses to angiotensin and norepinephrine in normal man. Effect of sodium intake. Circ Res. 31: 750-757.

20. Slick, G. L., G. F. DiBona, and G. J. Kaloyanides. 1975. Renal blockade to angiotensin II in acute and chronic sodium-retaining states. J. Pharmacol. Exp. Ther. 195: $185-193$.

21. Williams, G. H., L. M. McDonnell, M. C. Raux, and N. K. Hollenberg. 1974. Evidence for different angiotensin II receptors in rat adrenal glomerulosa and rabbit vascular smooth muscle cells. Studies with competitive antagonists. Circ. Res. 34: 384-390.

22. Khairallah P. A., A. Toth, and F. M. Bumpus. 1970. Analogs of angiotensin II. II. Mechanism of receptor interaction. J. Med. Chem. 13: 181-184.

23. Regoli, D., W. K. Park, F. Rioux, and C. S. Chan. 1971. Antagonists of angiotensin. Substitution of an aliphatic chain to phenyl ring in position 8. Rev. Can. Biol. 30: 319-329.

24. Sarstedt, C. A., E. D. Vaughan, Jr., and M. J. Peach. 1975. Selective inhibition by des-1-asp 8-ile-angiotensin II of the steroidogenic response to restricted sodium intake in the rat. Circ. Res. 37: 350-358.

25. Goldstein, A., L. Aranow, and S. M. Kalman. 1968. Molecular mechanisms of drug action. In Principles of Drug Action. Harper \& Row, Publishers, New York. 1-108.

26. Bravo, E. L., M. C. Khosla, and F. M. Bumpus. 1974. Action of [1-des (aspartic acid), 8-isoleucine] angiotensin II upon the pressor and steroidogenic activity of angiotensin II. J. Clin. Endocrinol. Metab. 40: 530-533.

27. Khairallah, P. A. 1972. Action of angiotensin on adrenergic nerve endings: Inhibition of norepinephrine uptake. Fed. Proc. 31: 1351-1357.

28. Peach, M. J., F. M. Bumpus, and P. A. Khairallah. 1969. Inhibition of norepinephrine uptake in hearts by angiotensin II and analogs. J. Pharmacol. Exp. Ther. 167: $291-299$.

29. Steele, S. M., Jr., and J. Lowenstein. 1974. Differential effects of an angiotensin II analogue on pressor and adrenal receptors in the rabbit. Circ. Res. 35: 592-600. 